\title{
Spectrophotometric determination of active chlorine by the color of indophenolic compounds
}

\author{
(C) Svetlana E. Pratskova, ${ }^{{ }^{+}}$and Oksana E. Sirenko \\ Department of Analytical and Physical Chemistry. Chelyabinsk State University. St. Br. Kashirins, 129. \\ Chelyabinsk, 454001. Russia. Phone: +7 (351) 99-70-64.E-mail: se_pratskova@mail.ru
}

\begin{abstract}
*Supervising author; ${ }^{+}$Corresponding author Keywords: spectrophotometric analysis, active chlorine, indophenolic method.
\end{abstract}

\begin{abstract}
Chlorination is a method of disinfection and oxidation of organic impurities in water. Chlorine is present in aqueous solutions in various forms, which are formed as a result of the chlorination of water. Spectrophotometric methods are very important for determining small amounts of chlorine and its compounds. The article presents a modification of the classical indophenolic method. Determination of active chlorine should be carried out at room temperature, maintaining the solutions for 50 minutes, the $\mathrm{pH}$ range is $11.9 \pm 0.1$. The optimal concentration of reagents: 33-fold excess of $N$-phenanthranilic acid, 2-fold excess of sodium nitroprusside, and the concentration of ammonium chloride should be 4 to 7 times less than the concentration of active chlorine. The following interaction scheme was proposed: oxidation of ammonia to chloramine with hypochlorite, amination of $N$-phenanthanilate with the formation of sodium 4-amino- $N$ phenylanthranilate, oxidation of 4-amino- $N$-phenylanthranilate with sodium hypochlorite to an indamin compound, followed by complexation with sodium nitroprusside. The linearity range of the calibration curve is $1-23 \mathrm{mg} / 1$, the convergence is $2.3 \%$, the relative error is $1 \%$. The molar ratios of ions and oxidizing agents present in natural waters that do not interfere with the determination of active chlorine are investigated. The optimal concentrations of reagents, sequential variation of the concentration of solutions and fixing the change in light absorption were established. The ratio of the stoichiometric coefficients according to the reaction equation was: ammonium: $N$-phenanthranilic acid: sodium nitroprusside: hypochloride was 1: 2: 1: 1 . It is proposed to use this method to determine the active chlorine in tap water. It is recommended to use the calibration schedule to determine the preliminary content, and to establish a more accurate concentration, use the method of additives.
\end{abstract}

\section{References}

[1] Chemistry of industrial wastewater. edited by A. Rubin. Moscow: Chemistry. 1983. 525p. (russian)

[2] D.V. Budina, T.Ya. Ashikhmina, and A.S. Olkova. Toxic effects' analysis of water extracts of polyvinylchloride compounds. Butlerov Communications. 2017. Vol.50. No.6. P.112-118. DOI: 10.37952/ROI-jbc-01/17-50-6-112

[3] V.V. Ivanishchev, and N.N. Zhukov. Manifestations of oxidative stress in sprouts of triticale under condition of short-term exposure of sodium chloride. Butlerov Communications. 2017. Vol.52. No.11. P.123-130. DOI: 10.37952/ROI-jbc-01/17-52-11-123

[4] V.V. Ivanishchev, and N.N. Zhukov. On the interrelation of water exchange and photosynthesis in triticale sprouts with short-term action of sodium chloride. Butlerov Communications. 2018. Vol.53. No.3. P.35-42. DOI: 10.37952/ROI-jbc-01/18-53-3-35

[5] Yu.Yu. Lurie. Analytical chemistry of industrial wastewater. Moscow: Chemistry. 1984. 448p. (russian)

[6] M.I. Kievskiy, V.N. Evstratov, V.D. Semenyuk. Wastewater treatment of chlorine industry enterprises. Moscow: Chemistry. 1978. 190p. (russian)

[7] A.K. Babko, A.T. Pilipenko. Photometric analysis. Methods for the determination of non-metals. Moscow: Chemistry. 1974. 360p. (russian)

[8] I.D. Eremina, L.K. Shpigun, Yu.A. Zolotov. Flow injection analysis. Spectrophotometric determination of chloride ions in atmospheric precipitation. Journal of Analytical Chemistry. 1989. Vol.44. No.3. P.399-403. (russian)

[9] Colorimetric method for the determination of non-metals. edited by A.I. Busev. Moscow: Foreign literature. 1963. 467p. (russian) 
[10] A.T. Pilipenko, R.K. Gakal. Determination of elemental chlorine in water. Ukrainian Chemical Journal. 1974. Vol.40. No.3. P.528-533.

[11] N.I. Ismailov, A.Kh. Osmanova, N.V. Yusifova, M.V. Mammadova, and S.N. Osmanova. Associates of chlorotellurite with azo-substituted ethoxyacridine in extraction-photometric analysis. Butlerov Communications. 2017. Vol.50. No.6. P.137-140. DOI: 10.37952/ROI-jbc-01/17-50-6-137

[12] N.S. Frumina, N.F. Lysenko, M.A. Chernova. Analytical chemistry of elements. Chlorine. Moscow: Science. 1983. 200p. (russian) 